\title{
Strong hyperconjugative interactions limit solvent and substituent influence on conformational equilibrium: the case of cis-2-halocyclohexylamines
}

\author{
Camila B. Francisco ${ }^{1}$, Cleverton S. Fernandes ${ }^{1}$, Ulisses Z. de Melo ${ }^{1}$, Roberto Rittner², \\ Gisele F. Gauze ${ }^{1}$ and Ernani A. Basso*1
}

\author{
Full Research Paper \\ Address: \\ ${ }^{1}$ Chemistry Department, State University of Maringá, 5790, Maringá \\ 87020-900, Brazil and ${ }^{2}$ Chemistry Institute, University of Campinas, \\ 6154, Campinas 13083-970, Brazil \\ Email: \\ Ernani A. Basso* - eabassouem@gmail.com \\ * Corresponding author \\ Keywords: \\ conformational equilibrium; cyclohexane derivatives; dynamic NMR; \\ hyperconjugation; principal component analysis
}

\author{
Beilstein J. Org. Chem. 2019, 15, 818-829. \\ doi:10.3762/bjoc. 15.79 \\ Received: 21 January 2019 \\ Accepted: 20 March 2019 \\ Published: 01 April 2019 \\ Associate Editor: P. Schreiner \\ (C) 2019 Francisco et al.; licensee Beilstein-Institut. \\ License and terms: see end of document.
}

\begin{abstract}
The presence of strong stereoelectronic interactions involving the substituents in cis-2-substituted cyclohexanes may lead to results different from those expected. In this work, we studied the conformational behavior of cis-2-fluoro- (F), cis-2-chloro- (CI), cis-2bromo- (Br) and cis-2-iodocyclohexylamine (I) by dynamic NMR and theoretical calculations. The experimental data pointed to an equilibrium strongly shifted toward the ea conformer (equatorial amine group and axial halogen), with populations greater than $90 \%$ for $\mathbf{F}, \mathbf{C l}$ and $\mathbf{B r}$ in both dichloromethane- $d_{2}$ and methanol- $d_{4}$. Theoretical calculations (M06-2X/6-311++G(2df,2p)) were in agreement with the experimental, with no influence of the solvent or the halogen on the equilibrium. A principal component analysis of natural bond orbital energies pointed to the $\sigma^{*} \mathrm{C}-\mathrm{X}$ and $\sigma_{\mathrm{C}-\mathrm{H}}$ orbitals and the halogen lone pairs $\left(\mathrm{LP}_{\mathrm{X}}\right)$ as the most significant for the hyperconjugative interactions that influenced the equilibrium. The $\sigma_{\mathrm{C}-\mathrm{H}} \rightarrow \sigma^{*} \mathrm{C}-\mathrm{X}$ hyperconjugation and the interactions involving the $\mathrm{LP}_{\mathrm{X}}$ counterbalance each other, explaining the non-influence of the halogen on the conformational equilibrium. These interactions are responsible for the strong preference for the ea conformer in cis-2-halocyclohexylamines, being strong enough to restrain the shift in the equilibrium due to other factors such as steric repulsion or solvent effects.
\end{abstract}

\section{Introduction}

cis-2-Substituted cyclohexanes are interesting from the conformational point of view, since one of the substituents should be axial. Generally, bulky substituents prefer the equatorial position to avoid steric repulsions [1]. Nevertheless, two distinct groups may provoke a competition of interactions, with regard to their volumes and steric repulsions, and the particular effects of the solvation medium on them, besides the intrinsic stereoelectronic effects. The sum of these factors in a system may 
lead to results different from those expected by considering just simple generalizations [2-9].

In the case of cis-2-halocyclohexylamines, the balance of interactions occurs between an amine group, which is known to be sensitive to the solvent $[2,10,11]$, and the halogen, where the size increases considerably from $\mathrm{F}$ to $\mathrm{I}$.

Batchelor reported the solvent effects on cis-2-methylcyclohexylamine [11], where the variation from aprotic to protic solvent causes a significant shift in the equilibrium, changing the axial preference of the amine group, which becomes equatorial with the protonation of the nitrogen.

The variation in the halogen size is also expected to cause some effect on the conformational equilibrium. Freitas and co-workers have demonstred this effect on trans-1,2-dihalocyclohexanes [12], where the diequatorial repulsion between the bulky halogens make the diaxial conformer more stable. Similarly, in trans-2-halocyclohexanols the $\mathrm{OH}-\mathrm{X}$ interaction that stabilizes the diequatorial conformer loses strength for steric repulsions in going from $\mathrm{F}$ to I [13]. However, in the behavior observed by Basso and co-workers for cis-2-halocyclohexanols [14], the axial preference of the halogen (about 60-70\%) is not greatly affected by the increase in the halogen size. Instead, the equilibrium is influenced by solute-solvent hydrogen bonding with the hydroxy group.

Besides the classical effects, interactions such as hyperconjugation has been pointed out as relevant in several studies involving cyclohexane derivatives $[4,12,15-20]$. Since the positions of both bonding and antibonding orbitals of the substituents change with the ring inversion, a conformation where a given substituent favors these interactions by performing them more effectively, may, in fact, govern the equilibrium. The $\mathrm{C}-\mathrm{X}$ bonds have already been reported as excellent electron-density acceptors, and their presence in a system suggests the possibility of these interactions $[17,21]$.

Although there have been several works on the conformational preference of 1,2-disubstituted cyclohexanes [4,11-14,20,2229], cis-2-halocyclohexylamines have not yet been consistently studied. This is quite surprising, due to the possibilities of effects that add up or compete with each other in the presence of these two groups. This gap in the literature may be attributed to experimental difficulties in obtaining these derivatives.

Therefore, in this work, we developed the study of cis-2-fluorocyclohexylamine (F), cis-2-chlorocyclohexylamine (CI), cis-2bromocyclohexylamine (Br) and cis-2-iodocyclohexylamine (I), the latter being only theoretical (due to experimental diffi-

culties). We evaluated the conformational equilibrium between ae (axial amine group and equatorial halogen) and ea (equatorial amine group and axial halogen) conformers (Figure 1) by dynamic NMR (DNMR) and theoretical calculations.

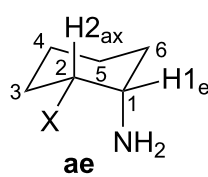

Figure 1: Conformations of cis-2-halocyclohexylamines, where $\mathrm{X}=\mathrm{F}$, $\mathrm{Cl}, \mathrm{Br}$ and $\mathrm{I}$.

\section{Results and Discussion \\ Experimental conformational population}

Low-temperature NMR experiments allow the identification of the individual conformers and their population at equilibrium, determined through the integration of ${ }^{1} \mathrm{H}$ and ${ }^{13} \mathrm{C}$ NMR spectra at $-80{ }^{\circ} \mathrm{C}$. Figure 2 illustrates the changes in the ${ }^{1} \mathrm{H}$ NMR spectra of cis-2-chlorocyclohexylamine in dichloromethane- $d_{2}$ by varying the temperature from 25 to $-80{ }^{\circ} \mathrm{C}$.

At $25^{\circ} \mathrm{C}$, the signal at $2.89 \mathrm{ppm}$ corresponds to $\mathrm{H} 1$, vicinal to nitrogen, and the signal at $4.32 \mathrm{ppm}$ to $\mathrm{H} 2$, vicinal to chlorine (Figure 2). These ${ }^{1} \mathrm{H}$ resonances, at room temperature, correspond to the average of the conformers at equilibrium. Table 1 shows the spectral data for $\mathbf{F}, \mathbf{C l}$ and $\mathbf{B r}$ at 25 and $-80{ }^{\circ} \mathrm{C}$, where ${ }^{3} J_{\mathrm{H}-\mathrm{H}}$ refers to the individual coupling constants with the vicinal hydrogens, and $\mathrm{W}$ is the sum of all couplings, the latter being useful when there is loss of definition or signal broadening, common in low-temperature experiments [29].

According to the coupling constants $\left({ }^{3} J_{\mathrm{H}-\mathrm{H}}\right)$ and half-height line widths (W) measured at $25^{\circ} \mathrm{C}$, the dominant conformation is ea. The higher values of $J$ and $\mathrm{W}$ for $\mathrm{H} 1$ indicate the diaxial coupling of this hydrogen with the axial hydrogen of C6 (Figure 1). This behavior was observed for all compounds, in both solvents, as shown in Table 1.

At $-80{ }^{\circ} \mathrm{C}$, two signals for $\mathrm{H} 1$ and $\mathrm{H} 2$ are observed, which correspond to ae $\left(\mathrm{H} 1_{\mathrm{ax}}\right.$ and $\left.\mathrm{H} 2_{\mathrm{eq}}\right)$ and ea $\left(\mathrm{H} 1_{\mathrm{eq}}\right.$ and $\left.\mathrm{H} 2_{\mathrm{ax}}\right)$ conformers individually (Table 1). The values of ${ }^{3} J_{\mathrm{H}-\mathrm{H}}, \delta$ and $\mathrm{W}$ at $-80{ }^{\circ} \mathrm{C}$ allow the assignment of the signals to the respective conformers, and by the integrals, determination the percentage of each in the equilibrium.

In the case of the bromine derivative, due to the broadening of both ${ }^{1} \mathrm{H}$ and ${ }^{13} \mathrm{C}$ signals and the loss of signal resolution at low temperature, the assignments at $-80{ }^{\circ} \mathrm{C}$ were made by considering the attributions at $25^{\circ} \mathrm{C}$. So, we assume the ea conformer 


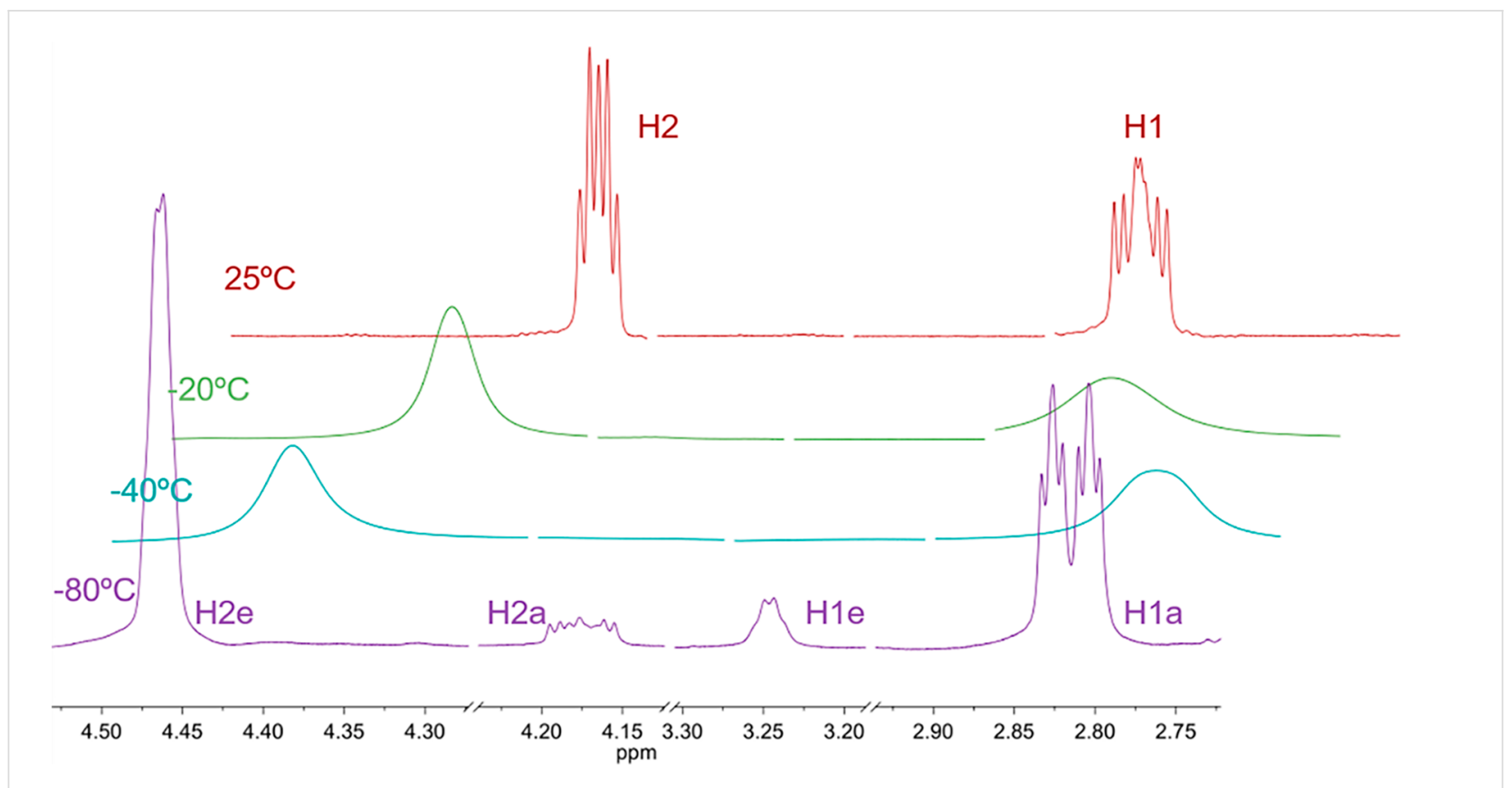

Figure 2: Variable-temperature ${ }^{1} \mathrm{H}$ NMR spectra $(500.13 \mathrm{MHz})$ for cis-2-chlorocyclohexylamine in dichloromethane- $d_{2}$.

\begin{tabular}{|c|c|c|c|c|c|c|c|c|c|c|c|}
\hline & & Hydrogen & $\delta^{a}$ & ${ }^{3} J_{\mathrm{H}-\mathrm{H}^{b}}$ & W & $\delta^{a}$ & ${ }^{3} J_{\mathrm{H}-\mathrm{H}^{b}}$ & W & $\delta^{a}$ & ${ }^{3} J_{H-H}$ & W \\
\hline & & & & Fluorine & & & Chlorine & & & Bromine & \\
\hline \multirow[t]{6}{*}{ dichloromethane- $d_{2}$} & \multirow[t]{2}{*}{$25^{\circ} \mathrm{C}$} & $\mathrm{H} 1$ & 2.73 & $10.21^{c}$ & 19.21 & 2.89 & 8.96 & 19.42 & 2.97 & 9.81 & 17.83 \\
\hline & & $\mathrm{H} 2$ & 4.60 & $4.74^{\mathrm{C}}$ & 11.36 & 4.32 & 5.72 & 12.99 & 4.68 & 5.65 & 11.10 \\
\hline & \multirow[t]{4}{*}{$-80^{\circ} \mathrm{C}$} & $\mathrm{H} 1_{\mathrm{ax}}$ & 2.62 & $11.86^{c}$ & 22.76 & 2.81 & 11.48 & 20.61 & 3.03 & d & d \\
\hline & & $\mathrm{H} 1_{\mathrm{eq}}$ & 3.37 & d & 16.89 & 3.25 & 3.33 & 10.54 & 3.52 & d & d \\
\hline & & $\mathrm{H} 2_{\mathrm{ax}}$ & 4.55 & d & 23.18 & 4.17 & 10.69 & 22.46 & 4.80 & $d$ & d \\
\hline & & $\mathrm{H} 2_{\mathrm{eq}}$ & 4.72 & d & 10.16 & 4.46 & d & 10.15 & 4.88 & $d$ & d \\
\hline \multirow[t]{6}{*}{ methanol- $d_{4}$} & \multirow[t]{2}{*}{$25^{\circ} \mathrm{C}$} & $\mathrm{H} 1$ & 2.70 & $10.83^{c}$ & 19.32 & 2.86 & 9.48 & 19.45 & 2.90 & $d$ & 18.53 \\
\hline & & $\mathrm{H} 2$ & 4.64 & $4.40^{\mathrm{C}}$ & 10.59 & 4.37 & 5.40 & 12.18 & 4.64 & 3.61 & 10.51 \\
\hline & \multirow[t]{4}{*}{$-80^{\circ} \mathrm{C}$} & $\mathrm{H} 1_{\mathrm{ax}}$ & 2.58 & $12.01^{\mathrm{c}}$ & 20.59 & 2.78 & 11.51 & 20.73 & 2.97 & d & d \\
\hline & & $\mathrm{H} 1_{\mathrm{eq}}$ & 3.21 & d & 12.52 & 3.10 & 3.31 & 11.32 & 3.32 & d & $d$ \\
\hline & & $\mathrm{H} 2_{\mathrm{ax}}$ & 4.48 & $d$ & 23.11 & 4.19 & 12.16 & 22.47 & 4.76 & $d$ & $d$ \\
\hline & & $\mathrm{H} 2_{\mathrm{eq}}$ & 4.65 & $2.56^{\mathrm{C}}$ & 8.10 & 4.41 & d & 8.10 & 4.67 & d & d \\
\hline
\end{tabular}

aln relation to TMS as reference. ${ }^{b}$ Largest $\mathrm{H}-\mathrm{H}$ coupling constant at three bonds. ${ }^{c}$ Measured considering only the ${ }^{3} J_{H-H}$ coupling, disregarding ${ }^{2} J_{H}-\mathrm{F}$. $\mathrm{d} J$ and $W$ were not measured due to loss of resolution or signals broadening at $-80^{\circ} \mathrm{C}$.

to be the major, attributing the most intense signals set at $-80{ }^{\circ} \mathrm{C}$ to this conformer.

The populations determined by the integration of both ${ }^{1} \mathrm{H}$ and ${ }^{13} \mathrm{C}$ NMR spectra at $-80{ }^{\circ} \mathrm{C}$ and the relative conformational energies are shown in Table 2. The equilibrium is shifted strongly toward the ea conformer, with $90 \%$ population for $\mathbf{F}$ and $\mathbf{C l}$ and $91 \%$ for $\mathbf{B r}$ in dichloromethane- $d_{2}$, while in metha- nol- $d_{4}$ the populations were 95,94 and $91 \%$ for $\mathbf{F}, \mathbf{C l}$ and $\mathbf{B r}$, respectively. These results clearly show that the equilibrium is non-sensitive to halogen size and solvent effects.

A similar axial preference of cyclohexane halo derivatives was observed by Basso and co-workers in cis-2-halocyclohexanols [14], and by de Oliveira and Rittner in trans-3-halocyclohexanols [30]. However, in both studies this preference was not so 
Table 2: Conformational populations and relative conformational energies of cis-2-halocyclohexylamines at $-80{ }^{\circ} \mathrm{C}$ in different solvents.

\begin{tabular}{|c|c|c|c|c|c|c|}
\hline & \multicolumn{2}{|c|}{${ }^{1} \mathrm{H}$} & \multicolumn{2}{|c|}{${ }^{13} \mathrm{C}$} & \multicolumn{2}{|c|}{ Average } \\
\hline & $\%$ ea & $\Delta G^{o a}$ & $\%$ ea & $\Delta G^{o a}$ & $\%$ ea & $\Delta G^{o a}$ \\
\hline & \multicolumn{6}{|c|}{$\mathbf{F}$} \\
\hline dichloromethane- $d_{2}$ & 90 & -0.84 & 90 & -0.84 & 90 & -0.84 \\
\hline \multirow[t]{2}{*}{ methanol- $d_{4}$} & 95 & -1.13 & 96 & -1.22 & 95 & -1.13 \\
\hline & \multicolumn{6}{|c|}{$\mathrm{Cl}$} \\
\hline dichloromethane- $d_{2}$ & 90 & -0.84 & 90 & -0.84 & 90 & -0.84 \\
\hline \multirow[t]{2}{*}{ methanol- $d_{4}$} & 93 & -0.99 & 95 & -1.13 & 94 & -1.06 \\
\hline & \multicolumn{6}{|c|}{$\mathrm{Br}$} \\
\hline dichloromethane- $d_{2}$ & 91 & -0.89 & $b$ & - & - & - \\
\hline methanol- $d_{4}$ & 91 & -0.89 & $\mathrm{~b}$ & - & - & - \\
\hline
\end{tabular}

${ }^{\mathrm{a}} \Delta G=-\mathrm{RT} \ln K$, where $K=n_{\mathrm{ea}} / n_{\mathrm{ae}}$ being $n_{\mathrm{ea}}$ the population of ea conformer and $n_{\mathrm{ae}}$ the population of ae conformer. A negative value means that ea is more stable. ${ }^{b}{ }^{13} \mathrm{C}$ integration was not possible due to signal broadening.

pronounced as that observed in this work, with a small difference between the populations of the two conformers at equilibrium.

The equatorial preference for the amine group was somehow expected, due to classical steric effects (syn-1,3-diaxial repulsion). On the other hand, the amine group is usually very sensitive to the solvent effect. In addition, the increase in the halogen size could lead to a shift toward the ae conformer (equatorial halogen). In the studied system, no change was observed, and this behavior suggests that other effects can be acting. So, theoretical calculations were performed in order to understand which mechanisms control the conformational preference of these compounds.

\section{Theoretical study}

\section{Conformer energy}

The potential energy surface (PES) for the dihedral C2-C1-N-H (M06-2X/aug-cc-pVDZ) shows that each conformer has three lower-energy rotamers, identified according to the orientation of the nitrogen lone pair as anti $(a)$ and gauche $(g \mathrm{X}$ and $g \mathrm{H})$ to $\mathrm{H} 1$ (Figure 3).

Optimization and frequency calculations were performed for these rotamers at different theory levels. A table showing the energies of each rotamer is available in Supporting Information File 1 (Table B1).

We compiled in Table 3 the energy differences between ea and ae conformers $\left(\Delta E_{\mathrm{ea}}\right)$, at four different theory levels, together

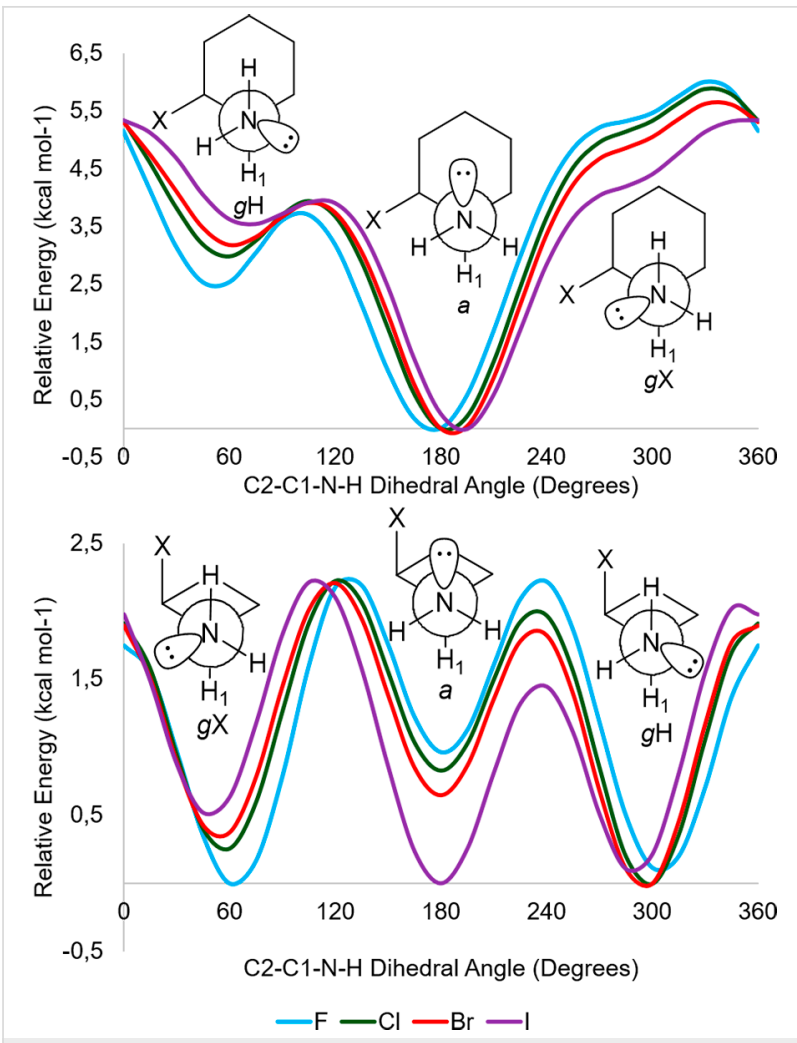

Figure 3: Potential energy surfaces (PESs) for cis-2-halocyclohexylamines for the $\mathrm{C} 2-\mathrm{C} 1-\mathrm{N}-\mathrm{H}$ dihedral angle rotation at M06-2X/aug-ccpVDZ in ae (top) and ea (bottom) conformers.

with the theoretical ea populations. The $\Delta E_{\text {ea }}$ values were calculated by the weighted averages of both conformers, considering the rotational populations in each. The negative values, both in 
gas phase and in solution, indicate that ea is the more stable conformation.

A trend in energy values was observed at all the theory levels employed in this study, there being a small decrease of $\Delta E_{\text {ea }}$ from gas phase to solution. However, when we compare the $\Delta E_{\text {ea }}$ values for dichloromethane and methanol, the energy variation is too small (Table 3). Likewise, the nature of the halogen also showed a minimal variation in $\Delta E_{\text {ea }}$ values over the series, both in gas phase and in solution. These energetical reports are in agreement with the experimental.

The calculations performed in M06-2X/6-311++G(2df,2p) showed results closer to the experimental, with the lower root mean square deviation (RMSD) error values of 0.004 in dichloromethane and 0.230 in methanol. This shows the efficiency of this theory level to describe the studied systems. The agreement of the energy values in gas phase with those in solution confers reliability to calculations such as natural bond orbitals (NBOs), which are made in the gas phase.
With regard to rotamers, $g \mathrm{X}$ in ae conformer and $a$ in ea are the least stable, with smaller populations (calculated in M06-2X/6$311++\mathrm{G}(2 \mathrm{df}, 2 \mathrm{p}))$, as shown in Figure 4. This was observed for the calculations performed in the gas phase, and in dichloromethane and methanol.

Even though previous works involving cyclohexane halo derivatives reported the axial preference of halogens, as mentioned before, the pronounced ea preference observed in our case led us to investigate the specific effects that may be responsible for this behavior.

\section{Delocalization, electrostatic and steric interactions}

In order to determine which effects are responsible for the stabilization of each conformer, we carried out studies of hyperconjugative, steric and electrostatic effects.

The deletion of all non-Lewis natural bond orbitals (M06-2X/6$311++\mathrm{G}, 2 \mathrm{df}, 2 \mathrm{p})$ disregard all hyperconjugative effects, allowing us to evaluate the conformational preference in the

\begin{tabular}{|c|c|c|c|c|c|c|c|}
\hline & & \multicolumn{2}{|c|}{ Gas phase } & \multicolumn{2}{|c|}{ Dichloromethane } & \multicolumn{2}{|c|}{ Methanol } \\
\hline & & $\Delta E_{\mathrm{ea}}$ & $\%$ ea & $\Delta E_{\mathrm{ea}}$ & $\%$ ea & $\Delta E_{\mathrm{ea}}$ & $\%$ ea \\
\hline \multirow[t]{4}{*}{ M06-2X/aug-cc-pVDZ } & $\mathrm{F}$ & -0.32 & 74 & -0.69 & 88 & -0.66 & 86 \\
\hline & $\mathrm{Cl}$ & -0.46 & 79 & -0.66 & 86 & -0.70 & 88 \\
\hline & $\mathrm{Br}$ & -0.49 & 81 & -0.89 & 92 & -0.88 & 92 \\
\hline & I & -0.48 & 81 & -1.02 & 94 & -1.06 & 94 \\
\hline $\mathrm{RMSD}^{\mathrm{a}}$ & & & & \multicolumn{2}{|c|}{0.131} & \multicolumn{2}{|c|}{0.270} \\
\hline \multirow[t]{4}{*}{ M06-2X/6-311++G(2df,2p) } & $\mathrm{F}$ & -0.36 & 76 & -0.67 & 86 & -0.69 & 87 \\
\hline & $\mathrm{Cl}$ & -0.49 & 80 & -0.76 & 89 & -0.77 & 90 \\
\hline & $\mathrm{Br}$ & -0.50 & 81 & -0.93 & 92 & -0.93 & 92 \\
\hline & I & -0.36 & 76 & -0.95 & 92 & -0.98 & 93 \\
\hline $\mathrm{RMSD}^{\mathrm{a}}$ & & & & \multicolumn{2}{|c|}{0.004} & \multicolumn{2}{|c|}{0.230} \\
\hline \multirow[t]{4}{*}{ MP2/aug-cc-pVDZ } & $\mathrm{F}$ & -0.22 & 71 & -0.61 & 78 & -0.73 & 88 \\
\hline & $\mathrm{Cl}$ & -0.22 & 70 & -0.64 & 85 & -0.68 & 87 \\
\hline & $\mathrm{Br}$ & -0.40 & 79 & -0.74 & 81 & -0.87 & 92 \\
\hline & I & -0.86 & 92 & -1.47 & 98 & -1.50 & 98 \\
\hline $\mathrm{RMSD}^{\mathrm{a}}$ & & & & \multicolumn{2}{|c|}{0.010} & \multicolumn{2}{|c|}{0.234} \\
\hline \multirow[t]{4}{*}{$M P 2 / 6-311++G(2 d f, 2 p)$} & $\mathrm{F}$ & -0.16 & 68 & -0.68 & 86 & -0.68 & 87 \\
\hline & $\mathrm{Cl}$ & -0.22 & 70 & -0.68 & 86 & -0.72 & 88 \\
\hline & $\mathrm{Br}$ & -0.17 & 67 & -0.64 & 85 & -0.62 & 85 \\
\hline & I & -0.16 & 66 & -0.63 & 85 & -0.63 & 86 \\
\hline $\mathrm{RMSD}^{\mathrm{a}}$ & & & & \multicolumn{2}{|c|}{0.013} & \multicolumn{2}{|c|}{0.264} \\
\hline
\end{tabular}

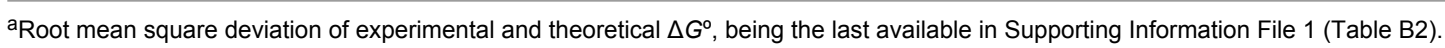




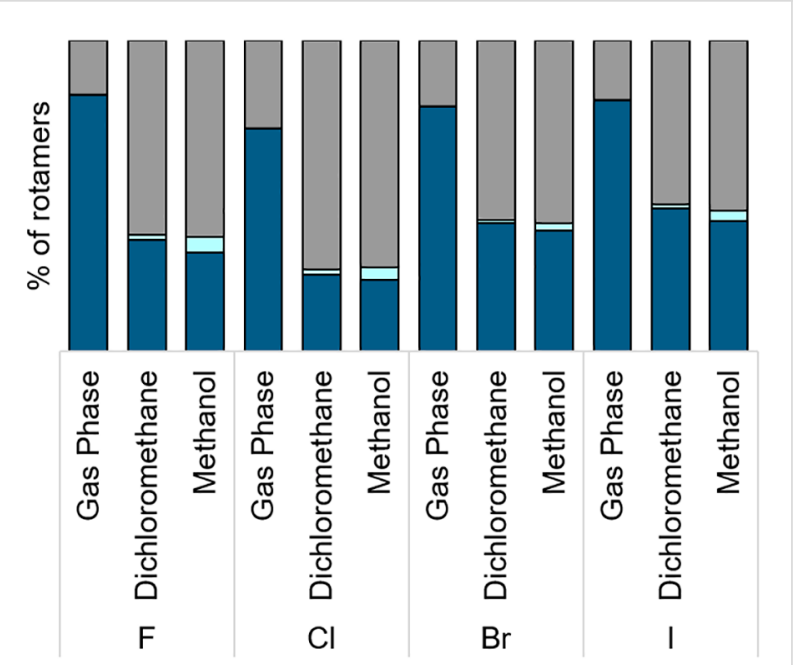

rotamers for each conformation were analyzed. The values of $\Delta E_{\text {deloc }}$ show an inversion of the conformational preference for all compounds in the absence of hyperconjugative interactions, and ae becoming the most stable conformer. It is worth noting the increase in the difference of the delocalization energy along the series, suggesting the influence of the halogen in this effect.

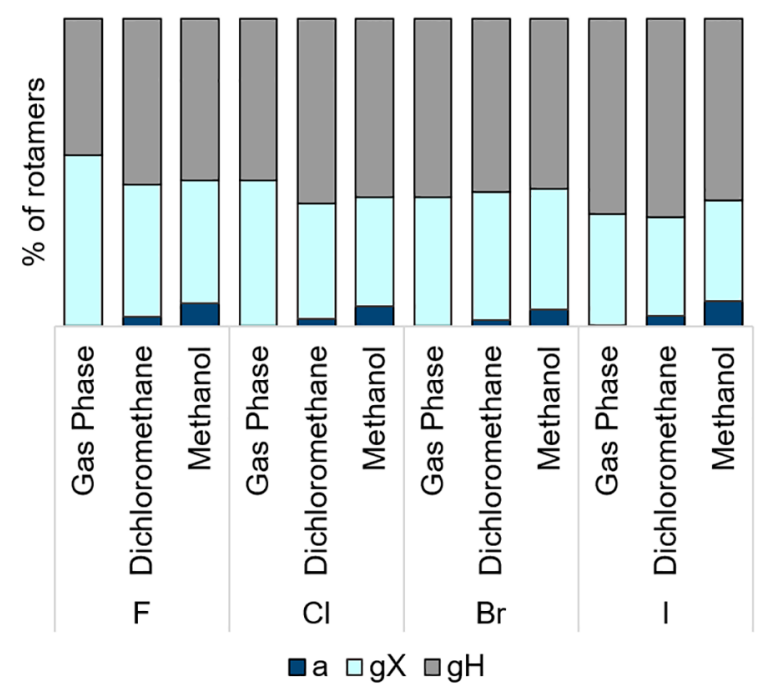

\begin{tabular}{|c|c|c|c|c|c|}
\hline & $\Delta E_{\text {total }^{a}}{ }^{\mathrm{a}}$ & $\Delta E_{\mathrm{loc}}^{\mathrm{a}}$ & $\Delta E_{\text {deloc }}{ }^{\mathrm{a}}$ & $E_{\text {steric }}{ }^{a}$ & $E_{\text {elect }}{ }^{b}$ \\
\hline & \multicolumn{5}{|c|}{ Fluorine } \\
\hline ae & 0.25 & 0.00 & 3.46 & 507.05 & -0.50 \\
\hline \multirow[t]{2}{*}{ ea } & 0.00 & 3.21 & 0.00 & 509.24 & -0.22 \\
\hline & \multicolumn{5}{|c|}{ Chlorine } \\
\hline ae & 0.25 & 0.00 & 5.77 & 527.16 & -0.13 \\
\hline \multirow[t]{2}{*}{ ea } & 0.00 & 5.52 & 0.00 & 532.02 & 0.18 \\
\hline & \multicolumn{5}{|c|}{ Bromine } \\
\hline ae & 0.32 & 0.00 & 7.56 & 534.05 & -0.09 \\
\hline \multirow[t]{2}{*}{ ea } & 0.00 & 7.24 & 0.00 & 535.73 & 0.25 \\
\hline & \multicolumn{5}{|c|}{ lodine } \\
\hline ae & 0.40 & 0.00 & 8.18 & 514.35 & -0.04 \\
\hline ea & 0.00 & 7.78 & 0.00 & 518.27 & 0.31 \\
\hline
\end{tabular}

aM06-2X/6-311++G(2df,2p) in the gas phase. ${ }^{b}$ Calculated using the Amber force field GAFF. Positive values indicate more repulsive interactions.

Figure 4: Populations of rotamers $a, g X$ e $g \mathrm{H}$ in ae (top) and ea (bottom) conformers of cis-2-halocyclohexylamines in the gas phase, dichloromethane and methanol.

absence of these interactions. Therefore, the total energy of each conformer $\left(E_{\text {total }}\right)$ can be expressed as the sum of $E_{\text {loc }}$, the localized energy after the deletion of the hyperconjugation, and $E_{\text {deloc }}$, the delocalization energy [31].

$$
E_{\text {total }}=E_{\text {loc }}+E_{\text {deloc }}
$$

These calculations also provide the total steric exchange energy ( $\left.E_{\text {steric }}\right)$, which describes the electron cloud repulsion [32]. Another parameter evaluated was the total electrostatic energy, $E_{\text {elect }}$, according molecular mechanics calculations employing the Amber force field GAFF [33].

So, after the deletion of hyperconjugative interactions, we should analyze the delocalization energy, where higher values indicate stronger effects. In Table 4 only the most stable

Taking into account the localized energy $\left(\Delta E_{\text {loc }}\right)$, the ea conformer presented the highest values, and it is consistent with the values of $E_{\text {steric }}$ and $E_{\text {elect }}$. It shows that, although ea is the most stable conformation, it has the greater steric and electrostatic repulsions.

Analyzing all these effects together, we could observe that hyperconjugation is an important factor to describe the conformational preference. Despite the evident influence of the halogen on hyperconjugation, the balance of these energies reflects in the unchanged equilibrium along the series.

With respect to the rotamers, neither hyperconjugation nor total steric exchange energies can explain the rotational behavior, which is attributed to electrostatic effects only. In the most unstable rotamers of each conformer ( $\mathrm{gX}$ for ae and $a$ for ea) the nitrogen electron lone pair is oriented toward the halogen, as illustrated in Figure 5, resulting in greater electrostatic repulsions. The values of localized, delocalized, steric and electro- 
static energies for all rotamers are available in Supporting Information File 1 (Table B3).

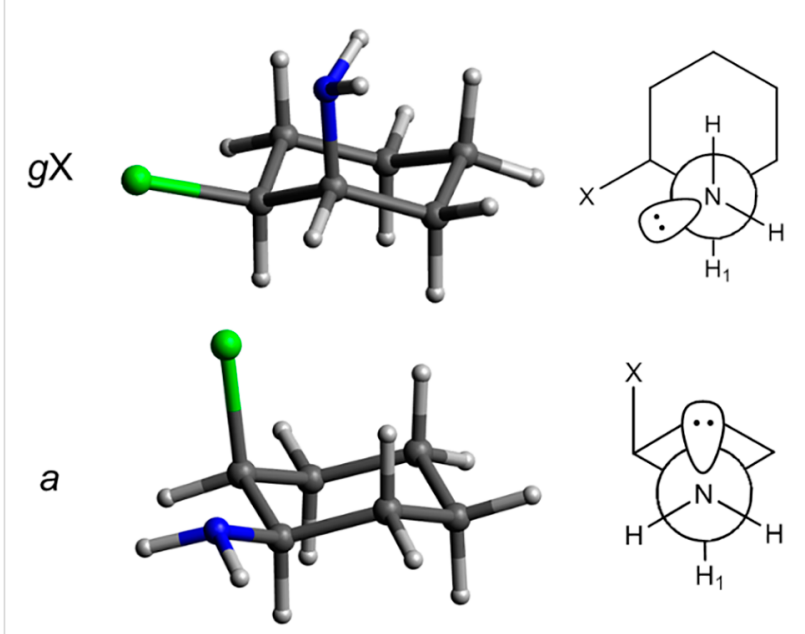

Figure 5: Nitrogen lone pair in rotamers $g X(a e)$ and a (ea) oriented towards the halogen, making these rotamers less stable in their respective conformation.

Although there is a sum of effects that can govern a conformational equilibrium, for cis-2-halocyclohexylamines the rotational preference is due to electrostatic effects, while the strong and non-sensitive conformational preference for ea can be explained by hyperconjugation. This arouses the interest for a deeper analysis of hyperconjugative interactions.

\section{Principal component analysis (PCA) of natural bond orbitals (NBOs)}

In order to interpretate the large number of interactions present in the compound structures, we applied PCA to NBO energies.

For each individual bond, the sum was made of all hyperconjugative stabilization energies $\left(E_{i j}\right)$ involving both bonding and antibonding orbitals, as well as the energies of nitrogen and halogen lone-pair interactions $\left(\mathrm{LP}_{\mathrm{N}}\right.$ and $\mathrm{LP}_{\mathrm{X}}$, respectively), resulting in 22 variables corresponding to all the bonds of the structure of the most stable rotamer in each conformation (see Supporting Information File 2 for full numerical data).

In the PCA (Figure 6), two principal components described $94 \%$ of the results. The PC1 is able to differentiate the variables according to the halogens, while the PC2 distinguish the two conformations.

The fact of the PC1, which has the higher variance in relation to the others, distinguish the halogens following a chemical trend is quite important, since the change in the halogen and consequently in the size of the orbitals directly affects the electronic delocalization.

According to the correlation vectors, the $\mathrm{LP}_{\mathrm{X}}$ differentiate the variables between the halogens, with the greater weight for the fluoro derivatives. If we analyse the vectors perpendicular to the groups of conformers, it is clear that the variables correspond-

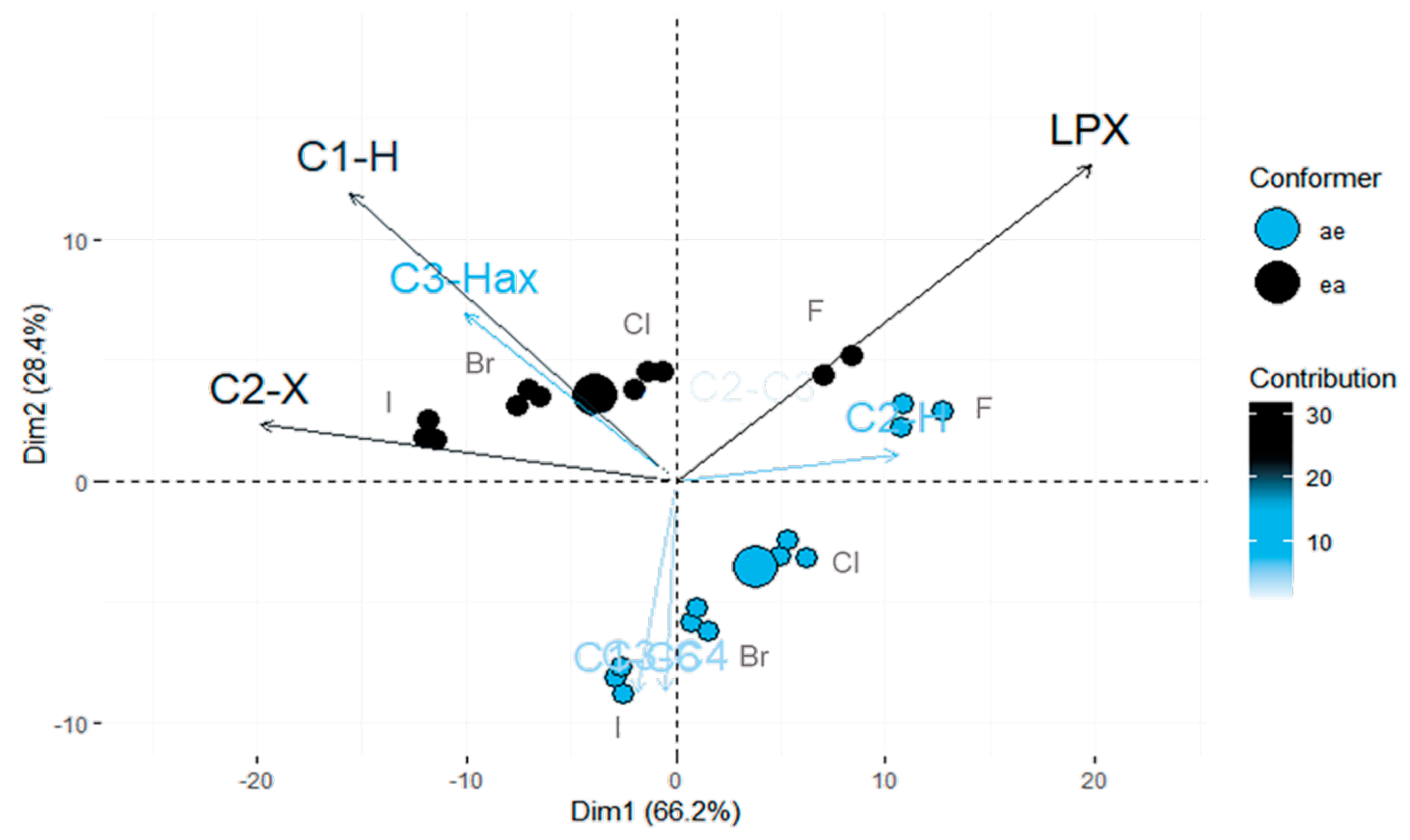

Figure 6: PCA for 22 variables corresponding to the hyperconjugative interactions for all rotamers in ae and ea conformers of cis-2-halocyclohexylamines. Note that the correlation vectors with the strongest black color has the greater contribution for the PC's. 
ing to $\mathrm{C} 1-\mathrm{H}, \mathrm{C} 2-\mathrm{X}$ and $\mathrm{C} 3-\mathrm{H}_{\mathrm{ax}}$ bonds distinguish the ea conformer from ae.

Then, considering all the interactions existent in both conformations, the ones involving the $\mathrm{LP}_{\mathrm{X}}$ are important for both conformers. However, what differs them are the interactions with the highest weight for ea.

It is worth mentioning that the variables corresponding to the $\mathrm{N}-\mathrm{H}$ bonds and $\mathrm{LP}_{\mathrm{N}}$ has no contribution for the PC's, confirming that the rotational preference has no influence on the hyperconjugation.

Analyzing the bonds pointed by the PCA as electron density donors (bonding orbitals) or acceptors (antibonding orbitals) in Figure 7 , it is clear that the most significant interactions are those involving the $\mathrm{C} 2-\mathrm{X}$ bond acting as electronic density acceptor $\left(\sigma^{*} \mathrm{C} 2-\mathrm{X}\right.$ orbital), and the $\mathrm{C} 1-\mathrm{H}\left(\sigma_{\mathrm{C} 1-\mathrm{H}}\right.$ orbital) and $\mathrm{LP}_{\mathrm{X}}$ acting as donor.

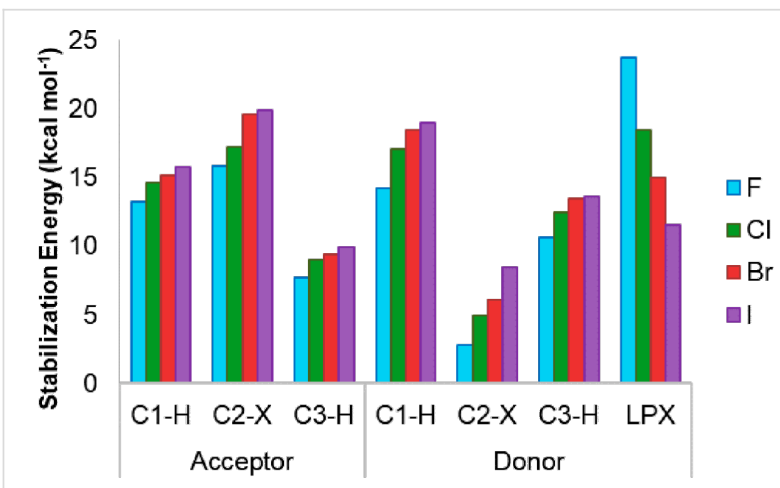

Figure 7: Sum of bonding (donor) and antibonding (acceptor) orbitals interactions of $\mathrm{C} 1-\mathrm{H}, \mathrm{C} 2-\mathrm{X}$ and $\mathrm{C} 3-\mathrm{H}_{\mathrm{ax}}$ bonds and $\mathrm{LP} \mathrm{P}_{\mathrm{X}}$ in cis-2-halocyclohexylamines.

This shows that hyperconjugative interactions are dependent on the halogen: as the size of the halogen increases, the donor or acceptor ability of the respective orbitals $(\mathrm{C}-\mathrm{X}$ bonds and antibonds) increases in the same way; however, the $\mathrm{LP}_{X}$ follows the reverse order, with a decrease in the donor ability as $\mathrm{LP}_{\mathrm{F}}>\mathrm{LP}_{\mathrm{Cl}}>\mathrm{LP}_{\mathrm{Br}}>\mathrm{LP} \mathrm{I}$

These observations allow us to analyze which specific orbitals are responsible for the great stabilization of the ea conformer. Table 5 presents the stabilization energy values $\left(E_{i j}\right)$, the difference in energy between the orbitals $\left(E_{i}-E_{j}\right)$ and the Fock matrix elements $\left(F_{(i ; j)}\right)$ for the main hyperconjugative interactions.

The $E_{i j}$ values for $\sigma_{\mathrm{C} 1-\mathrm{H}} \rightarrow \sigma^{*}{ }_{\mathrm{C} 2-\mathrm{X}}$ and $\sigma_{\mathrm{C} 3-\mathrm{Hax}} \rightarrow \sigma^{*}{ }_{\mathrm{C} 2-\mathrm{X}}$ clearly show a trend from $\mathbf{F}$ to $\mathbf{I}$, where these interactions
Table 5: Stabilization energy, $E_{i j}\left(\mathrm{kcal} \mathrm{mol}^{-1}\right)$, orbitals energy difference $E_{i}-E_{j}$ (a. u.) and Fock matrix elements $F_{(i, j)}$ (a. u.) of main hyperconjugative interactions in ea conformer of cis-2-halocyclohexylamines.

\begin{tabular}{|c|c|c|c|}
\hline & $E_{i j}$ & $E_{i}-E_{j}$ & $F_{(i, j)}$ \\
\hline \multicolumn{4}{|c|}{$\sigma_{\mathrm{C} 1-\mathrm{H}} \rightarrow \sigma^{*} \mathrm{C} 2-\mathrm{X}$} \\
\hline $\mathbf{F}$ & 5.83 & 0.86 & 0.063 \\
\hline $\mathrm{Cl}$ & 7.88 & 0.72 & 0.067 \\
\hline $\mathrm{Br}$ & 9.13 & 0.66 & 0.069 \\
\hline I & 9.44 & 0.64 & 0.069 \\
\hline \multicolumn{4}{|c|}{$\sigma_{\mathrm{C} 3-\mathrm{Hax}} \rightarrow \sigma^{*} \mathrm{C} 2-\mathrm{X}$} \\
\hline $\mathbf{F}$ & 5.99 & 0.87 & 0.065 \\
\hline $\mathrm{Cl}$ & 7.43 & 0.73 & 0.066 \\
\hline $\mathrm{Br}$ & 8.39 & 0.67 & 0.067 \\
\hline I & 8.34 & 0.65 & 0.066 \\
\hline \multicolumn{4}{|c|}{$\mathrm{LP}_{\mathrm{X}} \rightarrow \sigma^{*} \mathrm{C}-\mathrm{C}^{\mathrm{a}}$} \\
\hline $\mathbf{F}$ & 6.09 & 0.94 & 0.068 \\
\hline $\mathrm{Cl}$ & 4.36 & 0.79 & 0.053 \\
\hline $\mathrm{Br}$ & 3.40 & 0.76 & 0.046 \\
\hline I & 2.52 & 0.72 & 0.038 \\
\hline \multicolumn{4}{|c|}{$\mathrm{LP}_{\mathrm{X}} \rightarrow \mathrm{\sigma}^{*} \mathrm{C} 2-\mathrm{H} 8$} \\
\hline $\mathbf{F}$ & 6.26 & 0.97 & 0.069 \\
\hline $\mathrm{Cl}$ & 4.52 & 0.86 & 0.056 \\
\hline $\mathrm{Br}$ & 3.19 & 0.85 & 0.046 \\
\hline I & 2.15 & 0.81 & 0.037 \\
\hline
\end{tabular}

${ }^{\mathrm{a}} \sigma^{*} \mathrm{C} 2-\mathrm{C} 3$ for $\mathbf{F}$, and $\sigma^{*}{ }_{\mathrm{C} 1-\mathrm{C} 2}$ for $\mathrm{Cl}, \mathrm{Br}$ and $\mathbf{I}$.

become considerably more intense (higher $E_{i j}$ values) with the increase in the halogen size. It is also possible to observe that the difference in energy between these orbitals $\left(E_{i}-E_{j}\right)$ decreases from $\mathbf{F}$ to $\mathbf{I}$, which means that the acceptance of electron density by the $\mathrm{C}-\mathrm{X}$ bond is more effective when we have the larger halogens. The $E_{i}-E_{j}$ values decrease from 0.86 for $\mathbf{F}$ to 0.64 atomic units for $\mathbf{I}$ in $\sigma_{\mathrm{C} 1-\mathrm{H}} \rightarrow \sigma^{*}{ }_{\mathrm{C} 2-\mathrm{X}}$; and from 0.87 for $\mathbf{F}$ to 0.65 atomic units for $\mathbf{I}$ in $\sigma_{\mathrm{C} 3-\mathrm{Hax}} \rightarrow \sigma^{*}{ }_{\mathrm{C} 2-\mathrm{X}}$. The same trend is observed for the Fock matrix element $\left(F_{(i ; j)}\right)$, which concerns to the orbital overlap and also increases from $\mathbf{F}$ to $\mathbf{I}$.

On the other hand, the interactions involving the $\mathrm{LP}_{\mathrm{X}}$ follow the reverse order (Table 5). The $E_{i j}$ values decrease steadily from $\mathbf{F}$ to $\mathbf{I}$, going from 6.09 and 6.26 to 2.52 and $2.15 \mathrm{kcal} \mathrm{mol}^{-1}$ for $\mathrm{LP}_{\mathrm{X}} \rightarrow \sigma^{*} \mathrm{C}-\mathrm{C}$ and $\mathrm{LP}_{\mathrm{X}} \rightarrow \sigma^{*}{ }_{\mathrm{C} 2-\mathrm{H} 8}$, respectively. In the same way, the Fock matrix element decreases considerably comparing the $\mathrm{LP}_{\mathrm{F}}$ and $\mathrm{LP}_{\mathrm{I}}$ interactions, going from 0.068 and 0.069 for $\mathrm{LP}_{\mathrm{F}}$ to 0.038 and 0.037 atomic units for $\mathrm{LP}_{\mathrm{I}}$, in $\mathrm{LP}_{\mathrm{X}} \rightarrow \sigma^{*}{ }_{\mathrm{C}-\mathrm{C}}$ and $\mathrm{LP}_{\mathrm{X}} \rightarrow \sigma^{*}{ }_{\mathrm{C} 2-\mathrm{H} 8}$, respectively. 
This tendency in the halogen series observed in both hyperconjugative interactions describes the observed in PCA; the $\mathrm{LP}_{\mathrm{X}}$ interactions counterbalance the $\sigma_{\mathrm{C}-\mathrm{H}} \rightarrow \sigma^{*}{ }_{\mathrm{C} 2-\mathrm{X}}$, in the sense that the $\mathrm{LP}_{\mathrm{X}}$ is more important for the fluoro derivatives, while the $\sigma_{\mathrm{C}-\mathrm{H}} \rightarrow \sigma^{*} \mathrm{C} 2-\mathrm{X}$ has the greater weight for the larger halogens.

The acceptor ability of $\sigma^{*} \mathrm{C}-\mathrm{X}$ orbitals has already been described in the literature [17], and has an inverse correlation with electronegativity: the electronegativity decreases from $\mathbf{F}$ to $\mathbf{I}$ and the acceptor ability of $\sigma^{*} \mathrm{C}-\mathrm{X}$ orbitals increases in the order $\sigma^{*}{ }_{\mathrm{C}-\mathrm{F}}<\sigma^{*}{ }_{\mathrm{C}-\mathrm{Cl}}<\sigma^{*}{ }_{\mathrm{C}-\mathrm{Br}}<\sigma^{*} \mathrm{C}-\mathrm{I}$, as observed in this work.

As $\sigma_{\mathrm{C} 1-\mathrm{H}}, \sigma^{*} \mathrm{C} 2-\mathrm{X}$ and $\sigma_{\mathrm{C} 3-\mathrm{Hax}}$ are antiperiplanar, they favor orbital overlap, as illustrated in Figure 8. The orbital $\sigma^{*} \mathrm{C}-\mathrm{X}$ acting as electron density acceptor of $\sigma_{\mathrm{C} 1-\mathrm{H}}$ and $\sigma_{\mathrm{C} 3-\mathrm{Hax}}$ can explain the great axial preference of the halogens. While in the ea conformer the donors $\sigma_{\mathrm{C} 1-\mathrm{H}}$ and $\sigma_{\mathrm{C} 3-\mathrm{Hax}}$ are antiperiplanar to the acceptor $\sigma^{*} \mathrm{C}-\mathrm{X}$, in the ae conformer the corresponding donor orbitals are from $\mathrm{C}-\mathrm{C}$ bonds (due to equatorial halogen orientation). Previous publications have already reported the $\mathrm{C}-\mathrm{H}$ bond as slightly better donor than $\mathrm{C}-\mathrm{C}$ bond $[34,35]$.

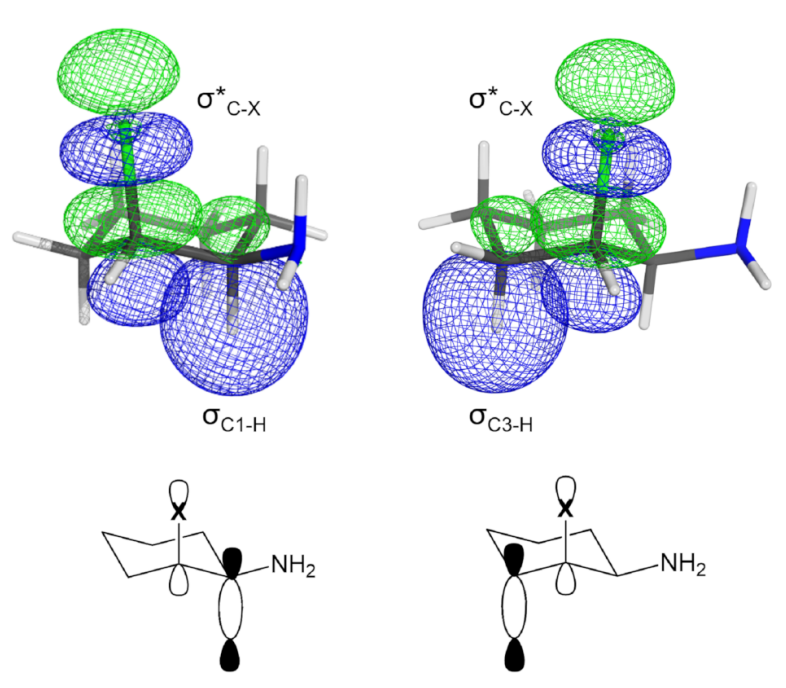

Figure 8: Orbitals overlap of $\sigma_{\mathrm{C} 1-\mathrm{H}} \rightarrow \sigma^{*} \mathrm{C} 2-\mathrm{X}$ (left) and $\sigma_{\mathrm{C} 3-\mathrm{Hax}} \rightarrow$ $\sigma^{*}{ }^{*}-\mathrm{X}$ (right) hyperconjugations in ea conformer.

Therefore, in the sum of interactions existent in the studied systems the hyperconjugation stands out, explaining the axial halogen and equatorial $\mathrm{NH}_{2}$ (ea) preference in all compounds.

\section{Conclusion}

The conformational behavior of the cis isomers of 2-fluoro-, 2-chloro- and 2-bromocyclohexylamine was determined experi- mentally through DNMR at $-80^{\circ} \mathrm{C}$, with populations of the ea conformer (equatorial amine group and axial halogen) higher than $90 \%$ in dichloromethane- $d_{2}$ and methanol- $d_{4}$. The conformational preference was affected neither by the solvent polarity nor the halogen size, suggesting the presence of strong stereoelectronic effects being responsible for the conformational behavior in these systems.

Theoretical calculations are in agreement with experimental data, the ea conformer being the most stable for all series, both in the gas phase and in solution. For the $\mathrm{C}-\mathrm{N}$ rotation, the most unstable rotamers are $g \mathrm{X}$ for the ae conformer and $a$ for ea, due to the orientation of the nitrogen lone pair electrons toward the halogen, which provides greater electrostatic repulsions.

The non-sensitivity to halogen size along the series can be attributed to a balance of steric, electrostatic and hyperconjugative interactions, being the strong conformational preference for ea explained by hyperconjugations involving mainly the $\mathrm{C}-\mathrm{X}$ bond. The greater acceptor ability of the $\sigma^{*} \mathrm{C}-\mathrm{X}$ orbital, axial in the ea conformer, enables strong interactions with the neighboring $\sigma_{\mathrm{C}-\mathrm{H}}$ orbitals, and this acceptor ability increases along the halogen series $(\mathrm{F}<\mathrm{Cl}<\mathrm{Br}<\mathrm{I})$. However, interactions involving the halogen lone pair electrons follows the reverse order, counterbalancing the $\sigma_{\mathrm{C}-\mathrm{H}} \rightarrow \sigma^{*} \mathrm{C}-\mathrm{X}$ interactions along the series.

The strongly shifted and non-sensitive conformational equilibrium governed by a strong hyperconjugative interaction in cis2-halocyclohexylamines shows that the conformational analysis of small molecules can still provide surprising results.

\section{Experimental \\ Synthesis}

trans-2-Fluorocyclohexanol was prepared according the literature [36] to provide cis-2-fluorocyclohexylamine.

cis-2-Fluorocyclohexylamine (F) was obtained by a Mitsunobu-Gabriel reaction, as described by Thvedt and co-workers [37]. Under nitrogen atmosphere, trans-2-fluorocyclohexanol $(6.00 \mathrm{mmol})$, triphenylphosphine $(6.60 \mathrm{mmol})$ and phthalimide $(6.60 \mathrm{mmol})$ were dissolved in THF $(40 \mathrm{~mL})$. To this mixture was slowly added a solution of diisopropyl azodicarboxylate (DIAD, 40\% in THF) and the mixture was stirred at room temperature for $18 \mathrm{~h}$. The solvent was removed under reduced pressure and the reaction mixture was re-dissolved in $\mathrm{CH}_{2} \mathrm{Cl}_{2}(20 \mathrm{~mL})$ and $10 \mathrm{~mL}$ of a $10 \% \mathrm{~K}_{2} \mathrm{CO}_{3}$ solution and stirred for $1 \mathrm{~h}$. The resulting mixture was washed with distilled water $(3 \times 10 \mathrm{~mL})$, the organic layer dried with $\mathrm{Na}_{2} \mathrm{SO}_{4}$ and concentrated under reduced pressure, and the crude product purified by silica-gel column chromatography (ethyl acetate/ 
hexane $20 \%)$, resulting in $1.18 \mathrm{~g}(80 \%)$ of the cis-Gabriel amine. The free amine was obtained by the hydrazinolysis of the cis-Gabriel amine $(0.40 \mathrm{mmol})$, in methanol $(0.50 \mathrm{~mL})$ with hydrazine hydrate $(25 \%, 0.20 \mathrm{~mL})$, stirred at room temperature for $24 \mathrm{~h}$. To the mixture was added $\mathrm{HCl}$ until $\mathrm{pH} \approx 2$, forming a precipitate, which was filtered, and to the aqueous phase was added $\mathrm{NaOH}$ until $\mathrm{pH} \approx 14$ and the product extracted exhaustively $(6 \times 10 \mathrm{~mL})$ with $\mathrm{CH}_{2} \mathrm{Cl}_{2}$. The organic layer was dried with $\mathrm{Na}_{2} \mathrm{SO}_{4}$ and the pure cis-2-fluorocyclohexylamine $(0.19 \mathrm{~g}, 35 \%)$, a yellowish liquid concentrated under reduced pressure.

2-Chloro- and 2-bromocyclohexanone were synthetized as previously described [38,39], to provide cis-2-chloro (CI) and cis2-bromocyclohexylamine $(\mathbf{B r})$, respectively, by a reductive amination [40].

To a sealed tube were added the corresponding ketone $(10 \mathrm{mmol})$, ammonium acetate $(100 \mathrm{mmol})$ and sodium cyanoborohydride $(10 \mathrm{mmol})$ in methanol $(30 \mathrm{~mL})$ and the mixture stirred for $48 \mathrm{~h}$ at room temperature. To the mixture was added concentrated $\mathrm{HCl}$ until $\mathrm{pH} \approx 2$, forming a white precipitate (protonated amine), which was filtered and dissolved in distilled water, which was washed with $\mathrm{CH}_{2} \mathrm{Cl}_{2}(3 \times 20 \mathrm{~mL})$. To the aqueous layer was added $\mathrm{NaOH}$ until $\mathrm{pH} \approx 14$ and the product extracted exhaustively with $\mathrm{CH}_{2} \mathrm{Cl}_{2}(6 \times 20 \mathrm{~mL})$. The crude mixture was purified by silica-gel column chromatography (acetone/chloroform $10 \%$ for $\mathbf{C l}$ and $25 \%$ for $\mathbf{B r}$ ), and the cis isomer was isolated corresponding to a yellowish liquid for $\mathbf{C l}$ $(0.04 \mathrm{~g}, 15 \%)$ and a white amorphous solid for $\mathbf{B r}(0.03 \mathrm{~g}$, $10 \%)$.

cis-2-Fluorocyclohexylamine: ${ }^{1} \mathrm{H}$ NMR $(500.13 \mathrm{MHz}$, methanol- $\left.d_{4}\right) \delta 4.64\left(\mathrm{dddd}, 1 \mathrm{H}, \mathrm{H}_{2}\right), 2.70\left(\mathrm{dddd}, 1 \mathrm{H}, \mathrm{H}_{1}\right), 2.01(\mathrm{~m}$, $\left.1 \mathrm{H}, 1 \mathrm{H}_{3}\right), 1.74-1.64\left(\mathrm{~m}, 2 \mathrm{H}, 1 \mathrm{H}_{5}, 1 \mathrm{H}_{6}\right), 1.61-1.42(\mathrm{~m}, 4 \mathrm{H}$, $\left.1 \mathrm{H}_{3}, 2 \mathrm{H}_{4}, 1 \mathrm{H}_{6}\right), 1.34\left(\mathrm{~m}, 1 \mathrm{H}, \mathrm{H}_{5}\right) ;{ }^{13} \mathrm{C} \mathrm{NMR}(125.77 \mathrm{MHz}$, methanol- $\left.d_{4}\right) \delta 93.58\left(\mathrm{C}_{2}\right), 52.80\left(\mathrm{C}_{1}\right), 30.84\left(\mathrm{C}_{3}, \mathrm{C}_{6}\right), 20.85$ $\left(\mathrm{C}_{4}\right), 24.88\left(\mathrm{C}_{5}\right)$; HRMS (ESI/QTOF) $\mathrm{m} / \mathrm{z}$ : $[\mathrm{M}+\mathrm{H}]^{+}$calcd for $\mathrm{C}_{6} \mathrm{H}_{12} \mathrm{FN}, 118.0953$; found, 118.0991 .

cis-2-Chlorocyclohexylamine: ${ }^{1} \mathrm{H}$ NMR $(500.13 \mathrm{MHz}$, dichloromethane- $\left.d_{2}\right) \delta 4.30\left(\mathrm{ddd}, 1 \mathrm{H}, \mathrm{H}_{2}\right), 2.80\left(\mathrm{ddd}, 1 \mathrm{H}, \mathrm{H}_{1}\right)$, $2.04\left(\mathrm{~m}, 1 \mathrm{H}, 1 \mathrm{H}_{3}\right), 1.78\left(\mathrm{~m}, 1 \mathrm{H}, 1 \mathrm{H}_{3}\right), 1.70-1.60\left(\mathrm{~m}, 2 \mathrm{H}, 1 \mathrm{H}_{5}\right.$, $\left.1 \mathrm{H}_{4}\right), 1,54\left(\mathrm{~m}, 2 \mathrm{H}, 2 \mathrm{H}_{6}\right), 1.40\left(\mathrm{~m}, 1 \mathrm{H}, 1 \mathrm{H}_{4}\right), 1.30\left(\mathrm{~m}, 1 \mathrm{H}, 1 \mathrm{H}_{5}\right)$; ${ }^{13} \mathrm{C}$ NMR $\left(125.77 \mathrm{MHz}\right.$, dichlorotmethane- $\left.d_{2}\right) \delta 68.47\left(\mathrm{C}_{2}\right)$, $53.22\left(\mathrm{C}_{1}\right), 33.16\left(\mathrm{C}_{3}\right), 31.30\left(\mathrm{C}_{6}\right), 23.76\left(\mathrm{C}_{5}\right), 21.10\left(\mathrm{C}_{4}\right)$; HRMS (ESI/QTOF) $m / z:[\mathrm{M}+\mathrm{H}]^{+}$calcd for $\mathrm{C}_{6} \mathrm{H}_{12} \mathrm{ClN}$, 134.0658; found, 134.0692 .

cis-2-Bromocyclohexylamine: ${ }^{1} \mathrm{H}$ NMR $(500.13 \mathrm{MHz}$, dichloromethane- $\left.d_{2}\right) \delta 4.68\left(\mathrm{ddd}, 1 \mathrm{H}, \mathrm{H}_{2}\right), 2.97\left(\mathrm{ddd}, 1 \mathrm{H}, \mathrm{H}_{1}\right)$, $2.18\left(\mathrm{~m}, 1 \mathrm{H}, \mathrm{H}_{3}\right), 1.93\left(\mathrm{~m}, 1 \mathrm{H}, \mathrm{H}_{3}\right), 1.77-1.63\left(\mathrm{~m}, 4 \mathrm{H}, 1 \mathrm{H}_{4}\right.$, $\left.1 \mathrm{H}_{5}, 2 \mathrm{H}_{6}\right), 1.50\left(\mathrm{~m}, 1 \mathrm{H}, \mathrm{H}_{4}\right), 1.37(\mathrm{~m}, 1 \mathrm{H}, \mathrm{H} 5) ;{ }^{13} \mathrm{C} \mathrm{NMR}$ $\left(125.77 \mathrm{MHz}\right.$, dichlorotmethane- $\left.d_{2}\right) \delta 62.19\left(\mathrm{C}_{1}\right), 53.42\left(\mathrm{C}_{2}\right)$, $33.67\left(\mathrm{C}_{3}\right), 30.08\left(\mathrm{C}_{5}\right), 23.87\left(\mathrm{C}_{6}\right), 21.28\left(\mathrm{C}_{4}\right)$; HRMS (ESI/ QTOF) $m / z$ : $[\mathrm{M}+\mathrm{H}]^{+}$calcd for $\mathrm{C}_{6} \mathrm{H}_{12} \mathrm{BrN}, 178.0153$; found, 178.0189 .

\section{NMR experiments}

${ }^{1} \mathrm{H}$ and ${ }^{13} \mathrm{C}$ NMR spectra were acquired on a Bruker Avance III HD spectrometer, operating at $500.13 \mathrm{MHz}$ for ${ }^{1} \mathrm{H}$ nuclei and 125.77 MHz for ${ }^{13} \mathrm{C}$ nuclei in solutions with approximate concentration of $0.01 \mathrm{~mol} \mathrm{~L}^{-1}$ in dichloromethane- $d_{2}$ and methanol$d_{4}$, using tetramethylsilane as internal reference. The probe was coupled to a liquid nitrogen evaporator system to decrease the temperature from 25 to $-80{ }^{\circ} \mathrm{C}$. Typical ${ }^{1} \mathrm{H}$ NMR spectra were run with a spectral window of approximately $10000 \mathrm{~Hz}$ (20 ppm) for ${ }^{1} \mathrm{H}$ spectra, and $30000 \mathrm{~Hz}(238 \mathrm{ppm})$ for ${ }^{13} \mathrm{C}$ spectra, with number of points $32 \mathrm{k}$, resulting in a digital resolution of $0.12 \mathrm{~Hz} /$ point. The spectral data are available in Supporting Information File 1.

\section{Theoretical calculations}

Theoretical calculations were performed with the software package Gaussian 09 [41]. To determine the lowest energy structures for each conformer, we built a PES (in M06-2X/augcc-pVDZ), varying the $\mathrm{C} 2-\mathrm{C} 1-\mathrm{N}-\mathrm{H}$ dihedral angle in steps of $15^{\circ}$ manually, to avoid nitrogen inversion.

Optimization and frequency calculations were performed for the three lower-energy rotamers for each conformer, both in the gas phase and in solution (Cartesian coordinates are available in Supporting Information File 1). The calculations were performed using the M06-2X density functional method, and the second-order Möller-Plesset perturbation method (MP2), associated with the Pople 6-311++G(2df,2p), and Dunning aug-cc-pVDZ basis set. The mixed basis set function LanL2DZ-ECP was employed for the iodine atom. Solvation calculations were performed in dichloromethane and methanol, with the the implicit model IEF-PCM and the description of the molecular cavity through Bondi's atomic radii.

Molecular Mechanics calculations were performed using the software Avogadro 1.2.0 [42], employing the Amber force field GAFF [33].

NBO calculations were performed in the optimized structures in the gas phase (M06-2X/6-311++G(2df,2p)), through the module NBO 5.9 [43] from Gaussian 09. For the PCA, it was used the software R, version 3.5.0 [44], with the graphical interface RStudio, version 1.0.153 [45]. 


\section{Supporting Information}

\section{Supporting Information File 1}

${ }^{1} \mathrm{H}$ and ${ }^{13} \mathrm{C}$ NMR spectra at 25 and $-80{ }^{\circ} \mathrm{C}$, supplementary

theoretical values, RScript for PCA and the Cartesian

coordinates of the structures.

[https://www.beilstein-journals.org/bjoc/content/

supplementary/1860-5397-15-79-S1.pdf]

\section{Supporting Information File 2}

NBO data for PCA.

[https://www.beilstein-journals.org/bjoc/content/

supplementary/1860-5397-15-79-S2.xlsx]

\section{Acknowledgements}

The authors would like to thank the Brazilian Council for Scientific and Technological Development (CNPq) for the fellowships to E.A.B. and R.R., and for the scholarship to C.S.F.; and the Coordination for the Improvement of Higher Education Personnel (CAPES) for the scholarships to C.B.F. and U.Z.M. Thanks also go to the São Paulo Research Foundation (FAPESP) (Grant 2016/24109-0) for the financial assistance and to the National Center for High Performance Computing (CENAPAD-UFC) for the computational cluster disponibility.

\section{ORCID ${ }^{\circledR}$ iDs}

Camila B. Francisco - https://orcid.org/0000-0002-6274-3948 Cleverton S. Fernandes - https://orcid.org/0000-0003-1404-8964 Ulisses Z. de Melo - https://orcid.org/0000-0002-2776-4268 Roberto Rittner - https://orcid.org/0000-0002-4715-6139 Gisele F. Gauze - https://orcid.org/0000-0002-1971-1983 Ernani A. Basso - https://orcid.org/0000-0001-7554-5206

\section{References}

1. Eliel, E. L.; Samuel, H. W. Stereochemistry of Organic Compounds; Wiley-Interscience: New York, 1994.

2. de Oliveira, P. R.; Viesser, R. V.; Guerrero, P. G., Jr.; Rittner, R. Spectrochim. Acta, Part A 2011, 78, 1599-1605. doi:10.1016/j.saa.2011.02.010

3. de Oliveira, P. R.; Rittner, R. Spectrochim. Acta, Part A 2008, 70, 1079-1086. doi:10.1016/j.saa.2007.10.016

4. Duarte, C. J.; Freitas, M. P. J. Mol. Struct. 2009, 930, 135-139. doi:10.1016/j.molstruc.2009.05.004

5. Silla, J. M.; Freitas, M. P. Comput. Theor. Chem. 2012, 999, 89-92. doi:10.1016/j.comptc.2012.08.019

6. de Oliveira, P. R.; Rittner, R. Spectrochim. Acta, Part A 2005, 61, 1737-1745. doi:10.1016/j.saa.2004.07.004

7. Onoda, A.; Haruna, H.; Yamamoto, H.; Takahashi, K.; Kozuki, H.; Okamura, T.-a.; Ueyama, N. Eur. J. Org. Chem. 2005, 641-645. doi:10.1002/ejoc.200400385

8. Lambert, K. M.; Stempel, Z. D.; Wiberg, K. B.; Bailey, W. F. Org. Lett. 2017, 19, 6408-6411. doi:10.1021/acs.orglett.7b03287
9. Kleinpeter, E.; Werner, P.; Linker, T. Tetrahedron 2017, 73, 3801-3809. doi:10.1016/j.tet.2017.04.029

10. Eliel, E. L.; Della, E. W.; Williams, T. H. Tetrahedron Lett. 1963, 4, 831-835. doi:10.1016/s0040-4039(01)90724-5

11. Batchelor, J. G. J. Chem. Soc., Perkin Trans. 2 1976, 1585. doi:10.1039/p29760001585

12. Freitas, M. P.; Rittner, R.; Tormena, C. F.; Abraham, R. J. Spectrochim. Acta, Part A 2005, 61, 1771-1776. doi:10.1016/j.saa.2004.07.007

13. Freitas, M. P.; Tormena, C. F.; Rittner, R. J. Mol. Struct. 2001, 570 , 175-180. doi:10.1016/s0022-2860(01)00482-3

14. Basso, E. A.; Abiko, L. A.; Gauze, G. F.; Pontes, R. M. J. Org. Chem. 2011, 76, 145-153. doi:10.1021/jo101819u

15. Taddei, F.; Kleinpeter, E. J. Mol. Struct.: THEOCHEM 2004, 683, 29-41. doi:10.1016/j.theochem.2004.06.010

16. Ribeiro, D. S.; Rittner, R. J. Org. Chem. 2003, 68, 6780-6787. doi:10.1021/jo034421।

17. Alabugin, I. V.; Zeidan, T. A. J. Am. Chem. Soc. 2002, 124, 3175-3185. doi:10.1021/ja012633z

18. Taddei, F.; Kleinpeter, E. J. Mol. Struct.: THEOCHEM 2005, 718, 141-151. doi:10.1016/j.theochem.2005.01.003

19. de Melo, U. Z.; dos Santos Yamazaki, D. A.; de Araújo Cândido, A.; Basso, E. A.; de Freitas Gauze, G. J. Mol. Struct. 2018, 1163, 227-235. doi:10.1016/j.molstruc.2018.01.096

20. Lopes Jesus, A. J.; Rosado, M. T. S.; Redinha, J. S. Comput. Theor. Chem. 2011, 964, 32-39. doi:10.1016/j.comptc.2010.11.031

21. Alabugin, I. V.; dos Passos Gomes, G.; Abdo, M. A. Wiley Interdiscip. Rev.: Comput. Mol. Sci. 2019, 9, e1389. doi:10.1002/wcms.1389

22. Bocca, C. C.; Basso, E. A.; Fiorin, B. C.; Tormena, C. F.; dos Santos, F. P. J. Phys. Chem. A 2006, 110, 9438-9442. doi:10.1021/jp061502n

23. Basso, E. A.; Kaiser, C.; Rittner, R.; Lambert, J. B. Magn. Reson. Chem. 1994, 32, 205-209. doi:10.1002/mrc.1260320403

24. Allinger, N. L.; Pamphilis, N. A. J. Org. Chem. 1973, 38, 316-319. doi:10.1021/jo00942a024

25. Yoshida, Z.-i.; Nakagawa, K. Tetrahedron Lett. 1965, 6, 3753-3756. doi:10.1016/s0040-4039(01)99558-9

26. Silla, J. M.; Duarte, C. J.; Freitas, M. P.; Ramalho, T. C.; Cormanich, R. A.; Santos, F. P.; Tormena, C. F.; Rittner, R. Spectrochim. Acta, Part A 2011, 81, 359-362. doi:10.1016/j.saa.2011.06.023

27. Basso, E. A.; Kaiser, C.; Rittner, R.; Lambert, J. B. J. Org. Chem. 1993, 58, 7865-7869. doi:10.1021/jo00079a035

28. Silla, J. M.; Cormanich, R. A.; Duarte, C. J.; Freitas, M. P.; Ramalho, T. C.; Barbosa, T. M.; Santos, F. P.; Tormena, C. F.; Rittner, R. J. Phys. Chem. A 2011, 115, 10122-10127. doi:10.1021/jp206136t

29. Cedran, J. C.; dos Santos, F. P.; Basso, E. A.; Tormena, C. F. J. Phys. Chem. A 2007, 111, 11701-11705. doi:10.1021/jp075280k

30. de Oliveira, P. R.; Rittner, R. Magn. Reson. Chem. 2008, 46, 250-255. doi:10.1002/mrc. 2173

31. Reed, A. E.; Weinhold, F. Isr. J. Chem. 1991, 31, 277-285. doi:10.1002/ijch.199100032

32. Badenhoop, J. K.; Weinhold, F. J. Chem. Phys. 1997, 107, 5422-5432. doi:10.1063/1.475149

33. Wang, J.; Wolf, R. M.; Caldwell, J. W.; Kollman, P. A.; Case, D. A. J. Comput. Chem. 2004, 25, 1157-1174. doi:10.1002/jcc.20035 
34. Alabugin, I. V. J. Org. Chem. 2000, 65, 3910-3919. doi:10.1021/jo991622+

35. Alabugin, I. V.; Manoharan, M. J. Org. Chem. 2004, 69, 9011-9024. doi:10.1021/jo048287w

36. Wittig, G.; Mayer, U. Chem. Ber. 1963, 96, 329-341. doi:10.1002/cber.19630960141

37. Thvedt, T. H. K.; Fuglseth, E.; Sundby, E.; Hoff, B. H. Tetrahedron 2010, 66, 6733-6743. doi:10.1016/j.tet.2010.06.081

38. Lautens, M.; Bouchain, G. Org. Synth. 2002, 79, 251. doi:10.15227/orgsyn.079.0251

39. Allinger, J.; Allinger, N. L. Tetrahedron 1958, 2, 64-74. doi:10.1016/0040-4020(58)88024-2

40. Borch, R. F.; Bernstein, M. D.; Durst, H. D. J. Am. Chem. Soc. 1971, 93, 2897-2904. doi:10.1021/ja00741a013

41. Gaussian 09, Revision B.01; Gaussian, Inc.: Wallingford, CT, 2010.

42. Hanwell, M. D.; Curtis, D. E.; Lonie, D. C.; Vandermeersch, T.; Zurek, E.; Hutchison, G. R. J. Cheminf. 2012, 4, 17. doi:10.1186/1758-2946-4-17

43. NBO 5.0; Theoretical Chemistry Institute, University of Wisconsin: Madison, 2001.

44. R: A Language and Environment for Statistical Computing, Version 3.5.0; R Foundation for Statistical Computing: Vienna, Austria, 2018.

45. RStudio: Integrated Development Environment for $R$, Version 1.0.5.153; RStudio Inc.: Boston, MA, 2016.

\section{License and Terms}

This is an Open Access article under the terms of the Creative Commons Attribution License

(http://creativecommons.org/licenses/by/4.0). Please note that the reuse, redistribution and reproduction in particular requires that the authors and source are credited.

The license is subject to the Beilstein Journal of Organic Chemistry terms and conditions:

(https://www.beilstein-journals.org/bjoc)

The definitive version of this article is the electronic one which can be found at: doi:10.3762/bjoc. 15.79 